\title{
An Assessment of Anti-hyperglycemic Drug Utilization Patterns and Adherence to AACE/ACE 2015 Guidelines in South Indian Tertiary Care Teaching Hospital
}

\author{
Siddhartha Nuthakki', Sivaprasad Pendyala', Charan Vallabhu', Naveenbabu Kilaru², Siva R Challa ${ }^{1,3}$, \\ Ravindrababu Pingili ${ }^{3}$
}

${ }^{1}$ Department of Pharmacy Practice, KVSR Siddhartha College of Pharmaceutical Sciences, Vijayawada, Andhra Pradesh, INDIA. 2Department of Microbiology, KVSR Siddhartha College of Pharmaceutical Sciences, Vijayawada, Andhra Pradesh, INDIA.

${ }^{3}$ Department of Pharmacology, KVSR Siddhartha College of Pharmaceutical Sciences, Vijayawada, Andhra Pradesh, INDIA.

\begin{abstract}
Aim: To compare adherence to American Association of Clinical Endocrinologists/American College of Endocrinology (AACE/ACE) 2015 guidelines for diabetes care in a tertiary care teaching hospital in India. Method: In this prospective observational study, 415 prescriptions of type 2 diabetes mellitus (T2DM) patients were collected in Dr. Pinnamaneni Siddhartha Institute of Medical Sciences (PSIMS) hospital from January 2015 and June 2015. Medication adherence to AACE/ACE guidelines was assessed based on glycated haemoglobin (HbA1C) values. Results: A total of 201 (48.4\%) male and $214(51.6 \%)$ female patients were identified. The mean age was $53.57 \pm 10.77$ years (male) and $53.69 \pm 10.71$ years (females). Patients with $\mathrm{HbA} 1 \mathrm{C}<7.5 \%(37.3 \%$, male; $45.3 \%$, female) were predominant followed by HbA1C $7.5 \%-9 \%(32.3 \%$, male; $35.3 \%$, female) and HbA1C > 9.0\% (30.4\%, male; $19.2 \%$, female). Hypertension (HTN) $(39.8 \%$, male; $39.7 \%$, female) is the most predominant co-morbidity, followed by patients with both HTN and cardio vascular diseases (CVDs) (9.4\%, male; $9.8 \%$, female). Insulin was prescribed to control hyperglycaemia in most of the cases $(40.0 \%)$ followed by dual therapy $(26.9 \%)$ and triple therapy $(17.8 \%)$. The overall adherence rate was $88.3 \%$ for patients with $\mathrm{HbA} 1 \mathrm{C}$ $<7.5 \%(\mathrm{P}<0.0001) ; 98.7 \%$ for patients with $\mathrm{HbA} 1 \mathrm{C} 7.5 \%-9 \%(\mathrm{P}<0.0001)$ and $100 \%$ for patients with $\mathrm{HbA} 1 \mathrm{C}$ $>9 \%(\mathrm{P}<0.0001)$. Conclusion: Optimal medication adherence is the ultimate goal to control the hyperglycemia in DM. The present study results revealed that the anti-diabetic medication adherence to AACE/ACE 2015 guidelines were optimal by the prescribers.
\end{abstract}

Key words:Type 2 Diabetes Mellitus, Medication adherence, HbA1C, AACE/ACE guidelines, Antihyperglycemicdrugs, Physician prescribing pattern.

\section{INTRODUCTION}

Diabetes mellitus (DM) is a most common metabolic disorder characterised by hyperglycemic. ${ }^{1}$ Worldwide prevalence of DM is estimated to rise from 382 million in 2013 to 592 million in $2035 .^{2}$ The prevalence of Type 1 diabetes (T1DM) is about $5 \%$ to $10 \%$ and type 2 diabetes mellitus (T2DM) is about $90 \%$ to $95 \%$. $^{3}$ There is no specific cause for DM, but both etiologic factors and risk factors are associated with it. The risk factors are heredity, obesity, increasing age, emotional stress, autoimmune $\nabla$-cell damage, endocrine diseases (e.g., Cushing disease).$^{4} \mathrm{DM}$ is one of the widely known risk factor for Peripheral vascular disease, CVD and Stroke. It also causes chronic complications like retinopathy, neuropathy and nephropathy. ${ }^{5}$ Until 1990s, the biguanide (metformin), the sulphonylureas and insulin were only the few drugs of choices available for the treatment of T2DM. Since then various other classes of drugs have been accepted. ${ }^{6}$ Now, hyperglycemic can be controlled through existing oral hypoglycaemic drugs and insulin by following some guidelines. The American Association of Clinical Endocrinologists/American College of
DOI: 10.5530/ijopp.9.4.3

Address for correspondence:

Siddhartha Nuthakki, KVSR Siddhartha College of Pharmaceutical Sciences, Vijayawada, Andhra Pradesh,520010, INDIA. Phone no: $+91-8500101122$ Fax: +91-866-2476086. E-mail:siddharthanuthakki@ gmail.com.

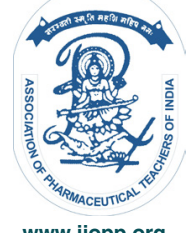

www.ijopp.org 
Endocrinology (AACE/ACE-2015) is considered the "gold standard" consensus guidelines for the management of DM. The other guidelines are 2015 American Diabetes Association (ADA) and 2015 National Institute for Health and Care Excellence (NICE). ${ }^{7-9}$ The most familiar principles of all these guidelines are to follow life style modification along with pharmacotherapy to manage hyperglycemic in patients with DM.In order to prevent severe complications with DM on long term, optimal adherence to drug therapy is necessary. Therefore, the objective of the study was to evaluate the antihyperglycemic drug prescribing pattern and their adherence to AACE/ACE 2015 guidelines in a south Indian tertiary care teaching hospital.

\section{METHODS}

\section{Experimental Design and Data collection procedure}

A prospective observational study was conducted at Dr. Pinnamaneni Siddhartha Institute of Medical Sciences (Dr.PSIMS), Andhra Pradesh and the protocol was approved by the Institutional ethics committee of the KVSR Siddhartha College of Pharmaceutical Sciences. A total of 415 prescriptions were collected from diabetic patients. Each prescription contained the drug, quantity, duration and date of dispensing. Each anti-diabetic medication was classified into one of the following classes: Metformin, Dipeptidyl peptidase-4 (DPP-4) Inhibitors, Glucagon-like peptide (GLP-1) receptor antagonists, Sodium-glucose co-transporter 2 (SGLT2) inhibitors, Alpha-glucosidase inhibitors (AGIs), Thiazolidinediones (TZD), Sulfonylureas (SUs) and Insulin. Medication adherence was assessed by comparing with AACE/ACE 2015 treatment guidelines shown in Figure 1.

\section{Statistical Analysis}

Statistical analysis was determined by using Graph pad (version 5.0, Chicago, USA) and SPSS 20 version. Patient characteristics and prescription details were compared using analysis of variance and $\bigotimes_{2}$ test for continuous and categorical variables, respectively. P-values $<0.05$ were considered statistically significant.

\section{RESULTS}

\section{Studied population characteristics}

A total of four hundred and fifteen prescriptions were collected in a period of six months to assess medication adherence. The demographic and clinical characteristics were shown in Table 1. A total of $201(48.4 \%)$ male and $214(51.6 \%)$ female patients were identified. T2DM was found to be almost equivalent in both male and female patients (Table 1). The mean age was $53.57 \pm 10.77$ years and $53.69 \pm 10.71$ years respectively. Patients with history of T2DM less than 5 years were dominant in both male $(49.8 \%)$ and female $(44.9 \%)$ gender followed by six to fifteen years and above 15 years of history. According to AACE/ACE guidelines T2DM was classified based on HbA1C levels and found to be $41 \%$ (HbA1C<7.5\%), 34\% (HbA1C 7.5\%-9\%) and 25\% (HbA1C $>9.0 \%)$. The mean $\mathrm{HbA1C}$ was $8.11 \pm 1.78$ (male) and $7.89 \pm 1.61$ (female). HbA1C $<7.5 \%$ (37.3\%, male; $45.3 \%$, female) was predominant followed by HbA1C 7.5\%-9\% (32.3\%, male; 35.3\%, female) and HbA1C $>9.0 \%$ (30.4\%, male; $19.2 \%$, female). HTN (39.8\%, male; $39.7 \%$, female) is the most predominant co-morbidity, followed by patients with both HTN and CVDs (9.4\%, male; 9.8\%, female). The average number of drug prescribed in each patient was 4-6 (66.7\%).

\section{Adherence to guidelines}

Table 2 shows the mono and combination therapies followed for the treatment of T2DM. The present study revealed that most of the physicians prescribed insulin therapy $(40.0 \%)$ to control hyperglycemic followed by dual therapy $(26.9 \%)$ and triple therapy $(17.8 \%)$. Metformin $(5.5 \%)$ is the most prescribed drug followed by DPP-4I (1.0\%) in monotherapy. Metformin+Sulfonyl Ureas (SU) and Metformin+SUs+Thiazolidinedion es (TZD) combination is most predominantly used in dual therapy and triple therapy respectively. The overall rate of adherence was $88.3 \%$ ( $\mathrm{HbA} 1 \mathrm{C}<7.5 \%)$; $98.7 \%$ (HbA1C 7.5\%-9\%) and 100\% (HbA1C >9\%) as shown in Table 3.

\section{DISCUSSION}

hyperglycemic is a very common metabolic disorder worldwide and is the leading cause of adult blindness and kidney failure in United States. The risk for myocardial infarction and cardiovascular death is increased by threefold to fourfold in diabetes patients respectively. Chronic microvascular complications like retinopathy, neuropathy and nephropathy can be prevented or delayed by effective management of chronic hyperglycemia. ${ }^{1,5}$ Benefits of successful management of glycaemic levels were witnessed over total range of $\mathrm{A} 1 \mathrm{C}$ values. United Kingdom Prospective Diabetes Study (UKPDS) reported that for every percentage point reduction in A1C there was 35\% reduction in risk for microvascular complications. ${ }^{1}$ The primary goal of DM management is to reduce diabetes associated mortality and to improve quality of life.

Indian Journal of Pharmacy Practice, Vol 9, Issue 4, Oct-Dec, 2016 


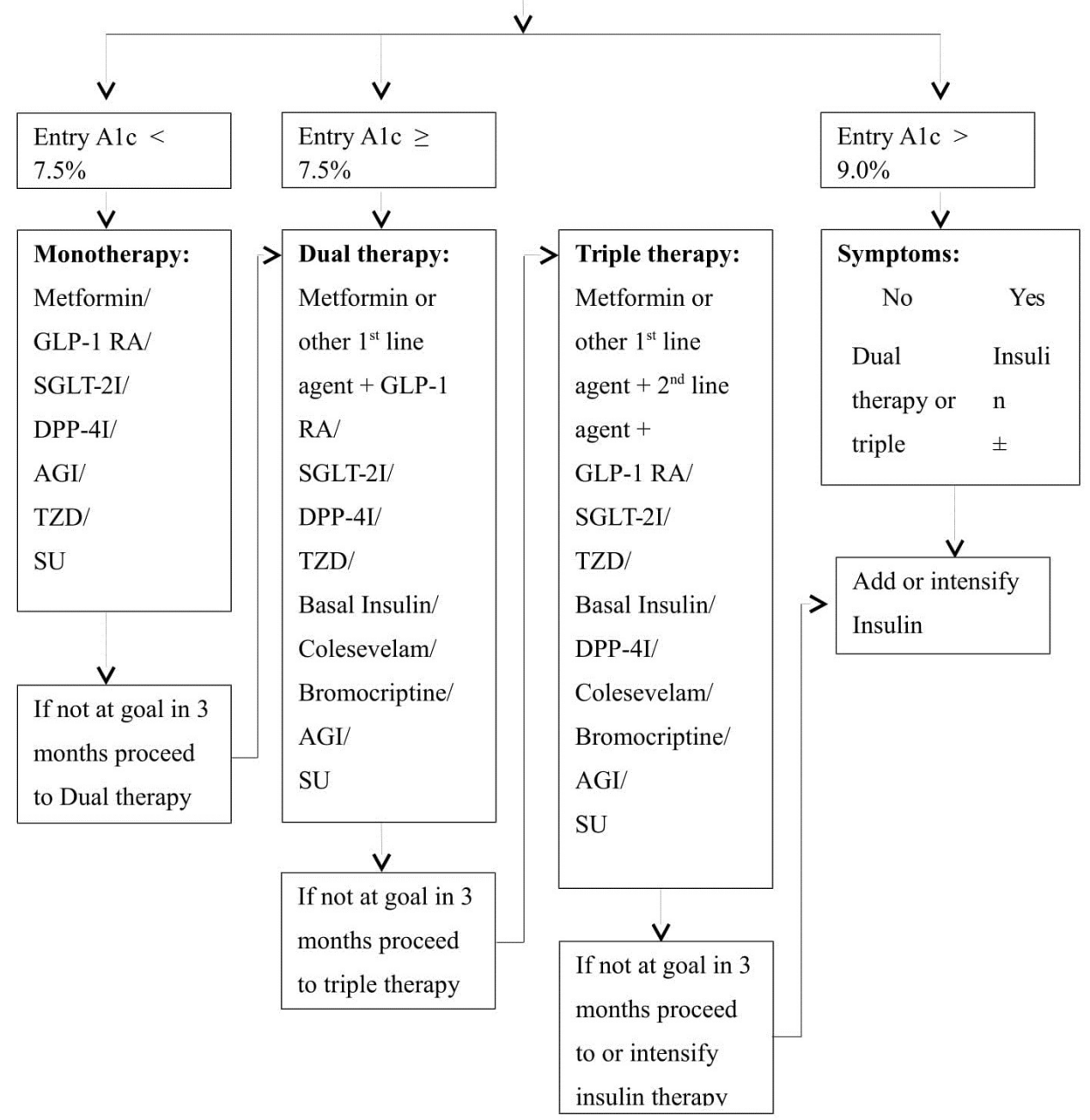

Figure 1: Algorithm for treatment of Diabetes mellitus according to AACE/ACE guidelines, 2015. GLP-1 RA, Glucagon-like peptide receptor antagonists; SGLT-2I, Sodium-glucose co-transporter 2 inhibitors; DPP-4I, Dipeptidyl peptidase 4 Inhibitors; AGI, Alpha-glucosidase inhibitors; TZD, Thiazolidinediones; SUs, Sulfonylureas.

Choice of an antihyperglycemic drug should be guided by anticipated benefits in an individual patient, taking into consideration the genetic, physiological and environmental factors that caused the disease, concurrent medical condition like hypertension, CVD, renal impairment, adverse effects of drugs and cost. AACE/ ACE 2015 recommendations for management of T2DM is the most prominent evidence based clinical guideline based on A1C levels. It is supplemented by National Institute for Health and Care Excellence (NICE) 2015. As per 2015 NICE guidelines, only Metformin, Pioglitazone, DPP-4i and SU are used in monotherapy. In contrary to that $2015 \mathrm{AACE} / \mathrm{ACE}$ recommends GLP-1 RA, SGLT-2I and AGI in monotherapy along with the above drugs shown in Figure 1. ${ }^{7}$ The results of the present study disclose the overall rate of adherence was 88.32\% (Monotherapy-HbA1C $<7.5 \%$ ); $98.76 \%$ (dual therapy-HbA1C 7.5\%-9\%); 100\% (Triple therapy and Insulin therapy $\mathrm{HbA1C}>9.0 \%)$. Some studies reported suboptimal adherence to standard guidelines. A study conducted in UK published those prescribers who followed NICE Diabetes prevention guidelines were able to achieve higher knowledge, awareness of diabetes in high risk patients when compared to their counter parts. ${ }^{10}$ Two studies reported that inadequate control of blood glucose levels are due to minimal adherence of prescribers to standard guidelines. ${ }^{11,12}$ However, many studies revealed that after publishing AACE/ACE guidelines there was significant difference in drug therapy based on A1c levels prescribed by physicians in United States of america. ${ }^{13}$ Another study published that there was optimal adherence to guidelines in Sweden in home health care settings than residents at nursing homes. ${ }^{14,15}$ This study found there was optimal adherence to AACE/ ACE guidelines in our institution resulting in better patient care. In dual therapy, triple and Insulin therapy there was unprecedented adherence. 


\begin{tabular}{|c|c|c|c|c|}
\hline Patient characteristics & $\begin{array}{c}\text { Males } \\
201(48.4 \%)\end{array}$ & $\begin{array}{c}\text { Females } \\
214(51.6 \%)\end{array}$ & Test & P-Value \\
\hline Age (Mean \pm SD) & $53.57 \pm 10.77$ & $53.69 \pm 10.71$ & t-test & 0.909 \\
\hline Below 40 years, $n(\%)$ & $27(13.4)$ & $29(13.55)$ & $x^{2}$ & - \\
\hline $41-60$ years, $n(\%)$ & $126(62.7)$ & $130(60.74)$ & $X^{2}$ & 0.891 \\
\hline Above 60 years, $n(\%)$ & $48(23.9)$ & $55(25.7)$ & $X^{2}$ & 0.845 \\
\hline $\begin{array}{l}\text { History of DM } \\
(\text { Mean } \pm \text { SD) }\end{array}$ & $7.63 \pm 6.72$ & $8.26 \pm 7.65$ & t-test & 0.204 \\
\hline $0-5$ years, $n(\%)$ & $100(49.8)$ & $96(44.9)$ & $X^{2}$ & - \\
\hline $6-15$ years, $n(\%)$ & $76(37.8)$ & $91(42.5)$ & $X^{2}$ & 0.295 \\
\hline Above 15 years, $n(\%)$ & $25(12.4)$ & $27(12.6)$ & $X^{2}$ & 0.705 \\
\hline $\begin{array}{c}\text { HbA1C } \\
(\text { Mean } \pm \text { SD) }\end{array}$ & $8.11 \pm 1.78$ & $7.89 \pm 1.61$ & t-test & 0.187 \\
\hline $\mathrm{A} 1 \mathrm{C}<7.5 \%, \mathrm{n}(\%)$ & $75(37.3)$ & $97(45.3)$ & $X^{2}$ & - \\
\hline A1C $7.5 \%-9 \%, n(\%)$ & $65(32.3)$ & $76(35.5)$ & $x^{2}$ & 0.658 \\
\hline $\mathrm{A} 1 \mathrm{C}>9.0 \%, \mathrm{n}(\%)$ & $61(30.4)$ & $41(19.2)$ & $x^{2}$ & 0.009 \\
\hline \multicolumn{5}{|c|}{ Co-morbid states } \\
\hline No (\%) & $81(40.3)$ & & $68(31.8)$ & \\
\hline $\operatorname{HTN}(\%)$ & $80(39.8)$ & & $85(39.7)$ & \\
\hline History of CVDs (\%) & $7(3.5)$ & & $12(5.6)$ & \\
\hline HTN and CVDs (\%) & $19(9.4)$ & & $21(9.8)$ & \\
\hline HTN and Thyroid (\%) & $9(4.5)$ & & $12(5.6)$ & \\
\hline Thyroid disorders (\%) & $5(2.5)$ & & $16(7.5)$ & \\
\hline \multicolumn{5}{|c|}{ Number of drugs in a prescription, $\mathrm{n}(\%)$} \\
\hline $1-3$ & \multicolumn{4}{|c|}{$36(8.7)$} \\
\hline $4-6$ & \multicolumn{4}{|c|}{$277(66.74)$} \\
\hline $7-9$ & \multicolumn{4}{|c|}{$101(24.33)$} \\
\hline$>10$ & \multicolumn{4}{|c|}{$1(0.24)$} \\
\hline
\end{tabular}

This study also revealed that Insulin therapy was mostly used in our hospital followed by two drug combination. Monotherapy was the least advised, the combination of metformin and SUs and Metformin, SUs and TZD were predominantly prescribed in Dual therapy and triple therapy respectively. This result was in accordance with the previous studies published demonstrating the order of mostly prescribed drug to be metformin, SUs and TZD. ${ }^{16-18}$ Increased use of insulin was observed in most of the patients due to presence of co-morbid conditions or resistance to oral hypoglycemic drugs. Increased insulin use was also observed in many other studies. ${ }^{19}$ Additionally, the use of DPP-4i was found to have significant importance in therapy. There were studies published that use of DPP-4i in both dual and triple therapy is safe and efficacious option. ${ }^{20-22}$

\section{CONCLUSION}

The dual therapy, triple therapy and insulin therapy was the corner stone for the better patient care. In the present study, there was an optimal adherence to AACE/ ACE 2015 guidelines by the physicians in our hospital.

\section{ACKNOWLEDGEMENTS}

The authors are grateful to N. Venkateswarlu, President and P. LakshmanaRao, Secretary of SAGTE for providing necessary facilities. The authors thank Dr. G. Devalarao, Principal and Dr. Buchi. N. Nalluri, Director for PG studies and Research of KVSR Siddhartha College of Pharmaceutical Sciences, Vijayawada for their encouragement.

\section{CONFLICT OF INTEREST}

The authors declare that this research does not have any conflict of interest with anyone or any Institute. 


\begin{tabular}{|c|c|}
\hline Treatment & n (\%) \\
\hline \multicolumn{2}{|l|}{ Monotherapy } \\
\hline $\begin{array}{c}\text { Metformin } \\
\text { DPP-4I } \\
\text { GLP-1 RA } \\
\text { SGLT-2I } \\
\text { AGI } \\
\text { TZD } \\
\text { SU/GLN }\end{array}$ & $\begin{array}{c}23(5.5) \\
4(1.0) \\
0(0) \\
0(0) \\
0(0) \\
0(0) \\
0(0)\end{array}$ \\
\hline \multicolumn{2}{|l|}{ Dual therapy } \\
\hline $\begin{array}{c}\text { Metformin or other } 1^{\text {st }} \text { line agent }+ \text { any othe } \\
\text { Metformin + DPP-4I } \\
\text { Metformin + SUs } \\
\text { Metformin + AGI } \\
\text { Metformin + TZD }\end{array}$ & $\begin{array}{c}2(0.5) \\
96(23.0) \\
4(1.0) \\
10(2.4)\end{array}$ \\
\hline \multicolumn{2}{|l|}{ Triple therapy } \\
\hline $\begin{array}{l}\text { Metformin or other } 1^{\text {st }} \text { line agent and second line ag } \\
\text { drug. } \\
\qquad \begin{array}{c}\text { Metformin + DPP-4I + SUs } \\
\text { Metformin + SUs + TZD } \\
\text { Metformin + SUs + AGI }\end{array}\end{array}$ & $\begin{array}{c}9(2.3) \\
62(15.0) \\
2(0.5)\end{array}$ \\
\hline \multicolumn{2}{|l|}{ Four drug combination } \\
\hline $\begin{array}{c}\text { Metformin + AGI + SUs +TZD } \\
\text { Metformin + DPP-4I + SUs + TZD }\end{array}$ & $\begin{array}{c}9(2.3) \\
27(6.5)\end{array}$ \\
\hline \multicolumn{2}{|l|}{ Insulin therapy } \\
\hline Insulin \pm Other agents & $(40.0)$ \\
\hline
\end{tabular}

\section{Table 3. Adherence of anti-diabetic medication to AACE guidelines}

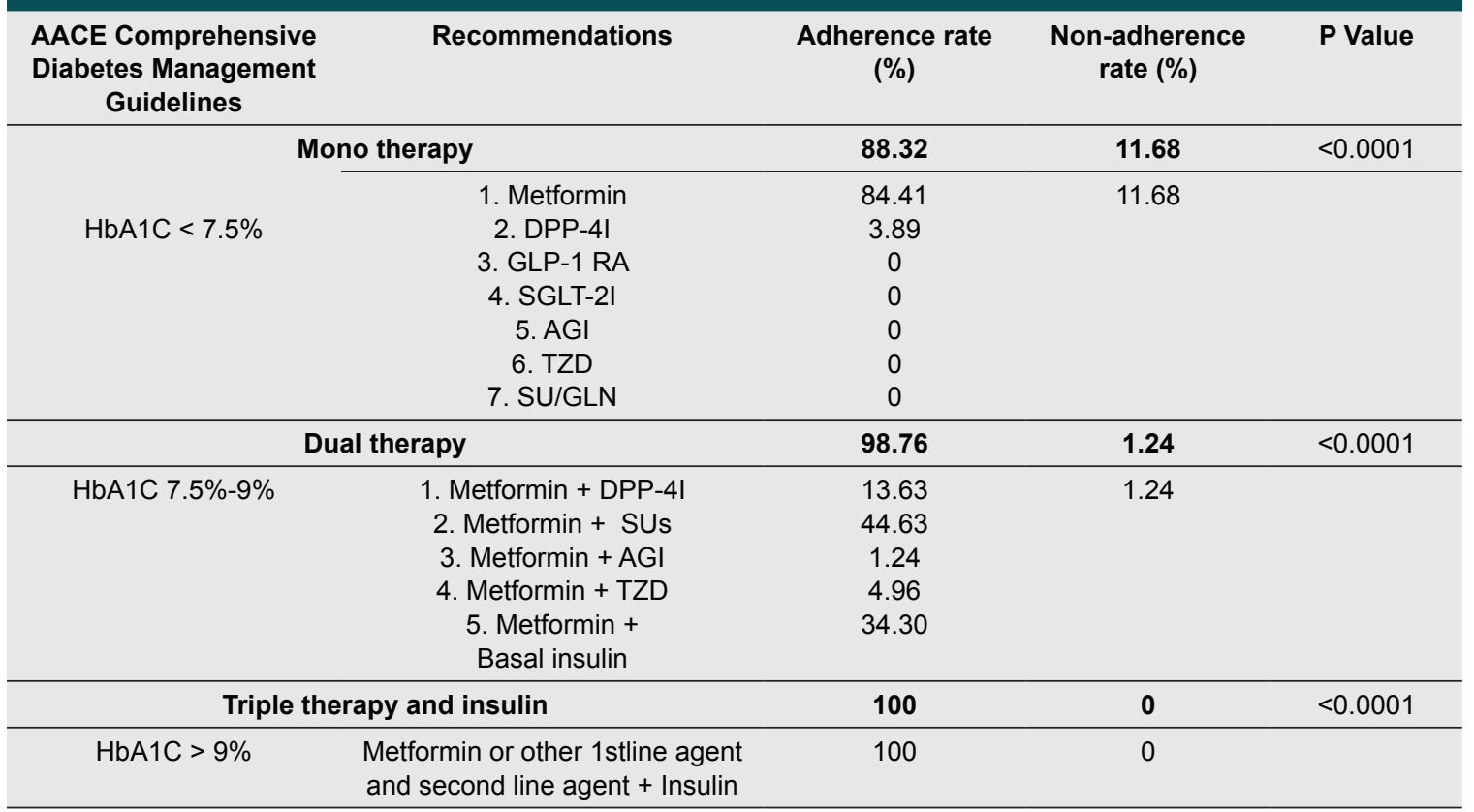

\section{ABBREVIATION USED}

AACE/ACE: American Association of Clinical Endocrinologists/American College of Endocrinology; ADA: American Diabetes Association; CVD: Cardio Vascular Diseases; DM: Diabetes Mellitus; HbAlc: Glycated hemoglobin; HTN: Hypertension; NICE: National
Institute of Health Care and Excellence; T1DM: Type 1 Diabetes Mellitus; T2DM: Type 2 Diabetes Mellitus.

\section{REFERENCES}

1. Dan LL, Anthony SF, Dennis LK, Stephen LH, Larry JJ, Joseph L. Harrison's Principles of Internal Medicine. Eighteenth edition, McGraw-Hill Medical, New York, United States of America; 2012, p. 2968. 
2. IDF Diabetes Atlas, 6thedition. 2013;1-160.

3. Bope ET, Kellerman RD. Conn's Current Therapy 2014. Saunders-Elsevier, Philadelphia, United States of America; 2014;701-704.

4. Richard AH.Diabetes Mellitus/Pathophysiology: Etiologic factors associated with diabetes mellitus. In: Stephen M Setter, John R White. Textbook of Therapeutics: Drug and Disease Management. Eigth Edition,Lippincott Williams and Wilkins-Wolters Kluwer, Philadelphia, United States of America; 2007.

5. Brian KA, Pamala AJ, Robin LC, Wayne AK, Michael EE, Bradley RW. KodaKimble and Young's applied therapeutics: The clinical use of drugs. Tenth edition, Lippincott Williams and Wilkins-Wolters Kluwer, Philadelphia, United States of America. 2013;1225-9.

6. Brian RW, Nicki RC, Stuart HR, Ian DP. Davidson's Principles and Practice ofMedicine. Twenty second edition, Churchill Livingstone-Elsevier, Edinburgh, United States of America. 2014;807-15.

7. Alan JG. AACE/ACE Comprehensive diabetes management algorithm 2015. Endocrine practice. 2015; 21(No.4).

8. William TC. Diabetes care. American Diabetes Association. Standards of medical care in diabetes-2015. The Journal of Clinical and Applied Research and Education. 2015;38(1):s1-s90.

9. NICE Clinical guideline-87. Type 2 diabetes. 2014

10. Nicola DG, NatarinC, Anne D, Gary SF. Adherence to NICE guidelines on diabetes prevention in the UK: Effect on patient knowledgeand perceived risk. Primary Care Diabetes. 2015;9(6):407-11. http://dx.doi.org/10.1016/j. pcd.2015.04.005; PMid:25979539.

11. Qasim MA, Ahmed SS, Ali MJ, Maha HI, Ekhlas KH, Saja MS. Adherence to the Standard Guidelines for Prescription of Antidiabetic Agents in Patients with Type 2 DM. Journal of Applied Pharmaceutical Science. 2012;2(7):138-43.

12. Turki J Al-H, Ayla MT, HeshamIAl-K, Adel MM, Hala Al-Q, Ahmed B. Adherence to the American Diabetes Association standards of care among the patients with type 2 diabetes in primary care in Saudi Arabia. Saudi Med J. 2015;36(2):221-7. http://dx.doi.org/10.15537/smj.2015.2.9603; PMid:25719589 PMCid:PMC4375702.

13. Rajesh $\mathrm{P}$, Ayoade $\mathrm{OA}$, Jamie $\mathrm{CB}$, Debra AL, Jason RJ. A retrospective observational analysis of clinical outcomes before and after the publication of AACE/ACE guidelines. International Journal of Clinical Medicine. 2014;5:71723. http://dx.doi.org/10.4236/ijcm.2014.512098.
14. Ann-Sofie NN, Lars B, Thomas N. Adherence to national diabetes guidelines through monitoring quality indicators-A comparison of three types of care for the elderly with special emphasis on HbA1c. Prim Care Diabetes. 2015;9(4):25360. http://dx.doi.org/10.1016/j.pcd.2015.03.002 ; PMid:25865853

15. Bela P, BhavitO, Kamlesh PP, Supriya DM, Varsha JP. Pattern of antidiabetic drugs use in type-2 diabetic patients in a medicine outpatient clinic of a tertiary care teaching hospital. Int J Basic ClinPharmacol. 2013;2(4):485-91. http:// dx.doi.org/10.5455/2319-2003.ijbcp20130826.

16. Mohammad SA, Mohammed A, Syed ASQ, PremK, Krishna KP. Utilization Pattern of Oral Hypoglycemic Agents for Diabetes Mellitus Type 2 Patients Attending Out-Patient Department at a University Hospital in New Delhi. Pharmacology \& Pharmacy. 2014;5(7):636-45. http://dx.doi.org/10.4236/ pp.2014.57073.

17. SudhaV, PrernaS, Patidar P, Bafna R,Jain S. Prescribing Pattern of Antidiabetic Drugs in Indore City Hospital. Indian J Pharm Sci. 2008;70(5):637-40. http:// dx.doi.org/10.4103/0250-474X.45404 ; PMid:21394262 PMCid:PMC3038290.

18. SayedAliulHA, ShobhaC,Ravi Kumar YS. Study of drug utilization pattern of antihyperglycemic agents in a South Indian tertiary care teaching hospital. Indian J Pharmacol. 2012;44(2):210-4. http://dx.doi.org/10.4103/02537613.93850 ; PMid:22529477 PMCid:PMC3326914.

19. Akshay AA, Pradeep RJ,Yeshwant AD. Prescribing pattern and efficacy of anti diabetic drugs in maintaining optimal glycemic levels in diabetic patients. J Basic Clin Pharm. 2014;5(3):79-83. http://dx.doi.org/10.4103/0976-0105.139731 ; PMid:25278671 PMCid:PMC4160724.

20. Barnett AH, Charbonnel B, Moses RG, Kalra S.Dipeptidyl peptidase-4 inhibitors in triple oral therapy regimens in patients with type 2 diabetes mellitus. Curr Med Res Opin. 2015;31(10):1919-31. http://dx.doi.org/10.1185/03007995.201 5.1081589 ; PMid:26361231

21. Kawalec P, Mikrut A, Łopuch S. The safety of dipeptidyl peptidase-4 (DPP4 ) inhibitors or sodium-glucose cotransporter 2 (SGLT-2) inhibitors added to metformin background therapy in patients with type 2 diabetes mellitus: a systematic review and meta-analysis. Diabetes Metab Res Rev.2014;30(4):26983. http://dx.doi.org/10.1002/dmrr.2494; PMid:24829965.

22. Guthrie RM. Clinical use of dipeptidyl peptidase-4 and sodium-glucose cotransporter 2 inhibitors in combination therapy for type 2 diabetes mellitus. Postgrad Med.2015;127(5):463-79. http://dx.doi.org/10.1080/00325481.2015.1 04475; PMid:25956345 